\title{
An additive effect of leading role in the organization between social participation and dementia onset among Japanese older adults: the AGES cohort study
}

Yuta Nemoto', Tami Saito², Satoru Kanamori ${ }^{3,4}$, Taishi Tsuji ${ }^{5}$, Kokoro Shirai $^{6}$, Hiroyuki Kikuchi ${ }^{3}$, Kazushi Maruo $^{7}$, Takashi Arao $^{8^{*}}$ (D) and Katsunori Kondo $5,9,10$

\begin{abstract}
Background: Several previous studies reported social participation may reduce the incident of dementia; therefore, the type of positions held in the organization may relate to dementia onset. However, this hypothesis remains largely unknown. The purpose of the present study was to examine the additive effect of a leadership position in the organization on dementia onset and social participation among elderly people in a local community, according to data from a Japanese older adults cohort study.

Methods: Of 29,374 community-dwelling elderly, a total of 15,313 subjects responded to the baseline survey and were followed-up from November 2003 to March 2013. To evaluate the association between dementia onset and social participation as well as the role in the organization, we conducted Cox proportional hazard regression analysis with multiple imputation by age group (aged 75 years older or younger). The dependent variable was dementia onset, which was obtained from long-term care insurance data in Japan; independent variables were social participation and the role in the organization to which they belonged (head, manager, or treasurer). Covariates were sex, age, educational level, marriage status, job status, residence status, alcohol consumption, smoking status, and walking time, instrumental activities of daily living, depression, and medical history.

Results: During the follow-up period, 708 young-old elderly people (7.7\%) and 1289 old-old elderly people (27.9\%) developed dementia. In young-old elderly, relative to social non-participants, adjusted Hazard Ratio (HR) for dementia onset for participants (regular members + leadership positions) was 0.75 ( $95 \%$ confidence interval (Cl), 0.64-0.88). Relative to regular members, adjusted HR for dementia onset for non-participants was 1.22 (95\% Cl, 1. 02-1.46), for leadership positions 0.81 ( $95 \% \mathrm{Cl}, 0.65-0.99$ ). The results for old-old elderly participants did not show that any significantly adjusted HR between dementia onset and social participation, the role in the organization.

Conclusions: In young-old elderly people, social participation might have a positive effect on dementia onset, and holding leadership positions in organization could lead to a decrease in risk of dementia onset by almost 20\% than regular members.
\end{abstract}

Keywords: Japan, Social participation, Leadership role, Dementia onset, Cohort study

\footnotetext{
*Correspondence: tarao@waseda.jp

${ }^{8}$ Faculty of Sports Sciences, Waseda University, $7359-1164$ Saitama

Prefecture, Tokorozawa, Mikajima, 2-579-15, Saitama, Japan

Full list of author information is available at the end of the article
} 


\section{Background}

The number of dementia patients has increased dramatically because of the aging population worldwide. In 2010, more than 35 million people developed dementia and it is estimated that increase to 115 million people in 2050 [1]. The population aging rate of Japan is $26.7 \%$ in 2015, and prevalence of dementia will increase from 2.8 million $(9.5 \%)$ in 2010 to 4.7 million (12.8\%) in 2025 [2].

Identifying factors related to dementia onset is fundamental for improving preventive strategies; several systematic reviews and meta-analyses have identified some modifiable factors related to cognitive function or dementia onset [3-5], and social participation is one of the factors related to dementia onset [5]. The following, which are promoted by social participation, decrease risk of dementia: increasing physical activity (leaving one's home), accessing emotional support by expanding social networks, and increasing frequency of cognitive activity by obtaining a social role [6]; however, most of them only focused on absence of social participation and dementia onset or cognitive function, and the additive effect of leadership positions remains largely unknown.

Some observational studies investigated the relationship between leadership positions and health status. According to Ishikawa et al. [7], holding leadership positions on the association was related to a $12 \%$ risk reduction of mortality. Takagi et al. [8] suggested that performing leadership positions was significantly related to low odds ratio (OR) for depression for women (OR, 0.57; 95\% CI, 0.37-0.88). Having leadership positions within civic groups may decrease the risk of dementia considerably; elderly people who manage the organization to which they belong perform various tasks or acquire roles that stimulate brain function or are beneficial to their health more so than compared with regular members, and this positively affects cognitive function.

The degrees of relationship between social participation and dementia onset may be different according to age group; in old-old (aged 75 or over), the age-related change has a greater effect on physical or mental health than in the young-old (aged 65-74) [9], and social participation can be a burden to the old-old. Therefore, to examine the relationship between social participation and dementia onset by age group is needed.

The purpose of the present study was to assess the additive effect of leadership positions in civic groups on the association between dementia onset and social participation among older adults in a local community, using data from a large cohort study (the Aichi Gerontological Evaluation Study: AGES).

\section{Methods}

\section{Data}

This study was based on data from the Aichi Gerontological Evaluation Study (AGES) project as a part of the Japan Gerontological Evaluation Study (JAGES). JAGES is a largely Japanese prospective cohort study aiming to find out the details of related factors for major health problems among the older adults, such as depression, dementia, or functional deterioration $[10,11]$.

\section{Participants}

Participants were chosen from within six municipalities in Aichi prefecture, consisting of urban, semi-urban, and rural settings. Out of 49,707 older adults aged 65 years and older in a local community who did not receive public long-term care insurance benefits, 29,374 individuals were selected using two methods: random sampling in two larger municipalities, and a complete survey in four semi-urban or rural municipalities. In October 2003, we conducted the baseline mail survey. A total of 15,313 individuals completed the baseline self-administrated questionnaire and followed up from November 2003 to March 2013. To identify the predictive factors for dementia onset, we involved relatively healthy older adults, and excluded individuals with any premonitory symptoms of dementia, such as being unable to walk, take a bath or use a toilet independently. Individuals who developed dementia within two years of the baseline were also excluded to clarify the relationship between dementia onset and initial conditions (Fig. 1).

The Ethics Committee on Research of Human Subjects at Nihon Fukushi University approved this study protocol.

\section{Measurements \\ Incident dementia}

Dementia onset was determined using disabling dementia, which is defined as incident functional disability with dementia. This was obtained from long-term care insurance data managed by local municipalities, as described previously [12]. Briefly, the degree of functional disability was evaluated according to a two-step procedure: on-site assessment of physical and mental condition by an agent from the home care provider, and further assessment by the Long-term Care Approval Board, consisting of health care professionals (doctors, nurses, caseworkers, or others) that referenced the results of on-site assessment and the primary physician's report, which is a standard form for assessing medical conditions and physical functions by a home physician [2]. Dementia was determined according to the Degree of Independence in Daily Living for Elderly with Dementia (Dementia Scale) [13, 14]. This scale was developed by the Japanese Ministry of Health, Labour 


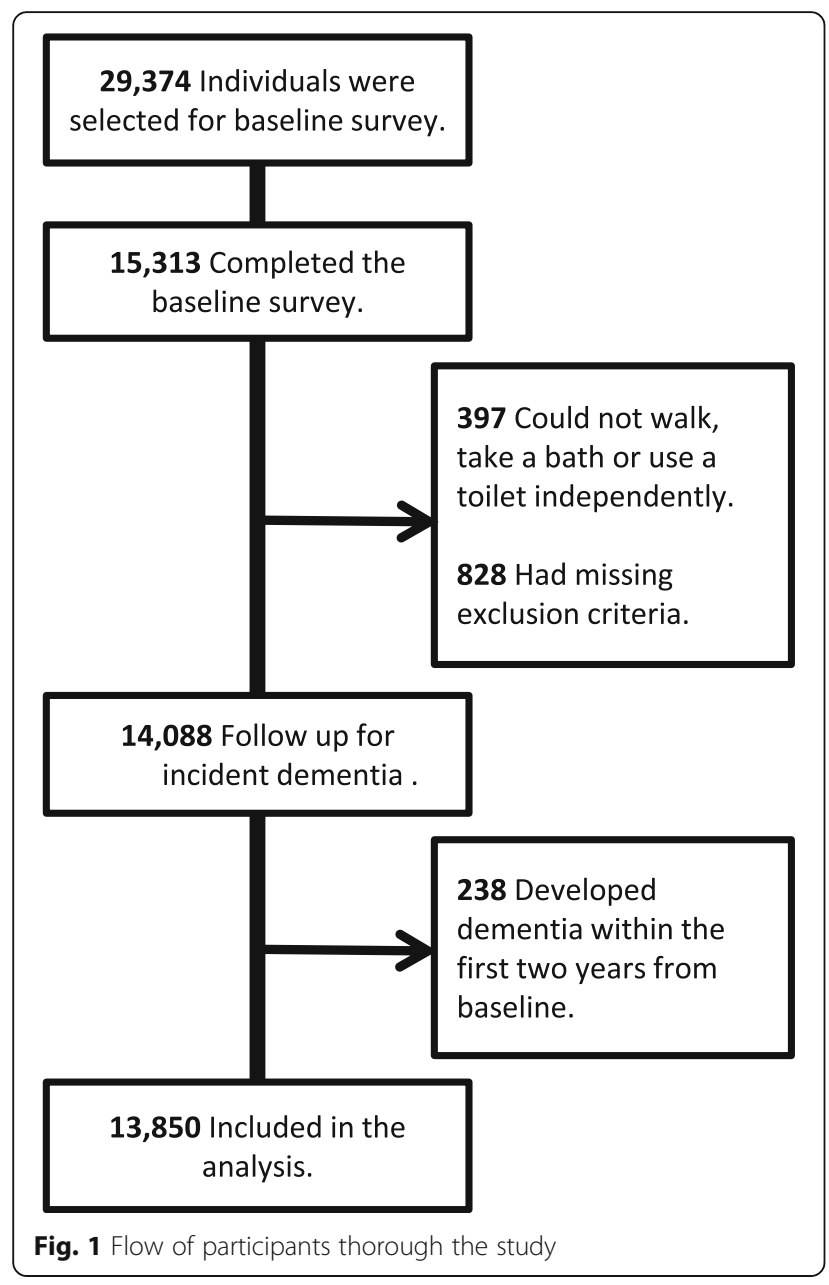

and Welfare, and health professionals in Japan use it to assess physical and cognitive function and classify individuals into levels I-IV and M. Level I means that the individuals have symptoms of dementia, but will be able to maintain an independent daily life. Level II indicates that the individuals show some symptoms and behaviors causing trouble in their daily life or some difficulties with communication, but could continue to live independently if monitored. Level III indicates that the individuals have the same symptoms as Level II patients, but more frequently, and sometimes require care to support their daily lives. Level IV indicates that the individuals have the same symptoms as in Level III, but more frequently, and always need care in their daily lives. Level $M$ indicates individuals with severe mental or physical diseases and behavioral disorders, who require specialized medical care. We defined individuals scoring levels II to IV or $M$ as having dementia. A previous study has shown that the Dementia Scale is well correlated with the Mini Mental State Exam score [15].

\section{Social participation and leadership positions in an organization}

The scale of social participation was taken from the Japanese General Social Survey [16], and categorized organizations into following eight types: neighborhood association, senior citizen club/fire-fighting team, religious group, political organization or group, industrial or trade association, volunteer group, citizen or consumer group, hobby group, and sports group or club. Participants were asked whether they were members of each association and their frequency of participation; those who answered "I do not participate in any organization" and "participate in the organization" but "very little" for frequency of participation were classified as "non-members". Therefore, the individuals who belonged to one or more associations were asked their position in the organization; those who serve as head, manager or treasurer were categorized as having "leadership positions", while others were classified as "regular members".

\section{Covariates}

In this study, demographic variables, health behavior, and health status were included as covariates.

Demographic variables consisted of sex, age (65-69, $70-74,75-79,80-84,85$ years and over), educational attainment (less than 10 years, 10 or more years), marital status (married, other), residential status (solitary, other), employment (worker, non-worker), health behavior including alcohol status (drinker, non-drinker), smoking status (smoker/ former smoker, never-smoker), walking time (less than $30 \mathrm{~min} /$ day, $30 \mathrm{~min} /$ day and longer), health status included instrumental ADLs (IADLs) (the subscale of Tokyo Metropolitan Institute of Gerontology Index of Competence: TMIG-IC [17]), medical history (heart disease, stroke, hypertension, diabetes), depression (Geriatric Depression Scale-Short Version, GDS-SV [18]). Those who earned full score for TMIG-IC were categorized as "high", the GDS-SV cut-off was 5, as in a previous study [19], and subjects who scored above the cut-off were categorized as "depressed".

\section{Statistical analysis}

To handle missing data, we carried out multiple imputation with full conditional specification, and created 50 multiply imputed datasets [20]. Imputed model included incident of dementia, social participation and leading positions, demographic variables, health behavior, and health status. Therefore, Cox proportional hazard models were used on these datasets. These estimates and their standard errors were combined using Rubin's rules [21], and Hazard Ratio (HR) or confidence interval (CI) was calculated. For comparison, Cox proportional hazards model was used on the subset of complete case data. 
We calculated HRs for incident of dementia according to social participation and by age group (young-old, old-old) using the Cox proportional hazards model to examine the relationship between these factors, and carried out a similar analysis model that exchanged social participation and leading role variables to assess the additive effects of leading positions. We used a level of significance of less than $5 \%$ in all analyses. SAS 9.4 (SAS Institute, Cary, NC) was used for all calculations.

\section{Results}

Of 29,374 individuals, 15,313 completed the baseline survey (response rate, 52.1\%). Non-responders were younger, and there was no difference between sexes. Of the 15,313 subjects, 13,850 were included in the analysis. A total of 1463 individuals were excluded from analysis; 397 could not walk, take a bath or use a toilet independently, 828 had missing exclusion criteria, and 238 developed dementia within the first two years from baseline (Fig. 1). The mean follow-up period was 7.9 years (standard deviation, 2.4 years), and the number of missing values across each variable varied between $0(0 \%)$ and $933(10.1 \%)$ in young-old, 0 (0\%) and 721 (15.6\%) in old-old; the total number of individuals who had incomplete data among the all variables was 2629 (28.5\%) in young-old and 1663 $(36.0 \%)$ in old-old. The number of individuals who died during follow-up was 1611 (17.5\%) in young-old and $1363(29.5 \%)$ in old-old.

Of the 13,850 subjects of the analysis, 9234 (66.7\%) were young-old and $4616(33.3 \%)$ were old-old. Of these young-old, 708 (7.7\%) developed dementia, 3003 (32.5\%) were non-members, 2514 (27.2\%) were regular members, 2784 (30.1\%) were in leadership positions, whereas in old-old, 1289 (27.9\%) developed dementia, 1774 (38.4\%) were non-members, 1289 (27.9\%) were regular members, and 832 (18.0\%) were in leadership positions (Table 1). Table 2 shows that the incidence of dementia onset increased with age. The incidence in each category of old-old individuals was much higher than in young-old participants.

The results of Cox proportional hazards model on the imputed data indicated that the crude HR for dementia onset for regular members or those holding leadership positions, compared with non-members, was 0.65 (95\% CI, 0.55-0.75), and adjusted HR was 0.75 (95\%CI, 0.64-0.88) in young-old, whereas crude HR was 0.73 (95\% CI, 0.64-0.82), but adjusted HR was non-significant in old-old (Table 3 ).

Table 4 shows the relationship between having a leading role and dementia onset. In young-old, both crude HR and adjusted HR for dementia onset for nonmembers, relative to regular members, were significant (crude HR, 1.38; 95\%CI, 1.15-1.65, adjusted HR, 1.22;
95\% CI, 1.02-1.46), and crude HR or adjusted HR for leadership positions were also significant (crude $\mathrm{HR}$, 0.76; 95\% CI, 0.61-0.94, adjusted HR, 0.76; 95\% CI, 0.65-0.99); however, in the old-old group, there was not significant adjusted HR.

\section{Discussion}

The present study showed that social activity nonmembers have a greater risk of incident dementia than social activity members, and members in leadership positions have a significantly lower risk compared with the non-leading members in the young-old group. However, in the old-old group, non-significant differences in dementia risk were observed. These findings seem to suggest that social participation might be effective for prevention of dementia, and this preventive effect could become stronger in the young-old group if leadership positions are taken.

Our findings are broadly consistent with those of previous studies. Kuiper et al. [4] assessed the relationship between social participation and incidence of dementia through meta-analysis. The results of this analysis revealed that individuals with less social participation had a higher risk of dementia onset relative to subjects with higher levels of social participation (RR, 1.41; 95\% CI, 1.13-1.75). Although the mechanism underlying the association between social participation and incidence of dementia was not identified, the following pathways were possible: 1) higher level of physical activity due to leaving the home may promote cognitive reserve [6], 2) frequent contact with others may cause positive emotional states such as increased self-esteem, social competence, and adequate mood, which lead to lower stress levels [22], 3) performing various activities (e.g., engaging in a hobby, calculating the scores of games) that stimulate cognitive function serves to prevent a cognitive decline ("use it or lose it" theory) [23]. The present study implies that social participation might have a suppressive effect on the incidence of dementia, but the effect may be different based on participation in social activities. Although the reasons for the additive effect of a leadership role on incidence of dementia are not fully understood, one reason might be the difference in the frequency of social participation. Compared with regular members, individuals who take on leadership roles such as president, facilitator or treasurer have more frequent opportunities for social participation, and also take responsibility for actions to manage group activities (e.g., holding meetings, planning activities, and communicating with regular members). In this study, the proportion of individuals engaging in group activities more than once a month was higher among those in leadership positions than regular members ( $81.7 \%$ vs $64.8 \%$, data not shown). Higher frequency of 
Table 1 Initial characteristics of the participants

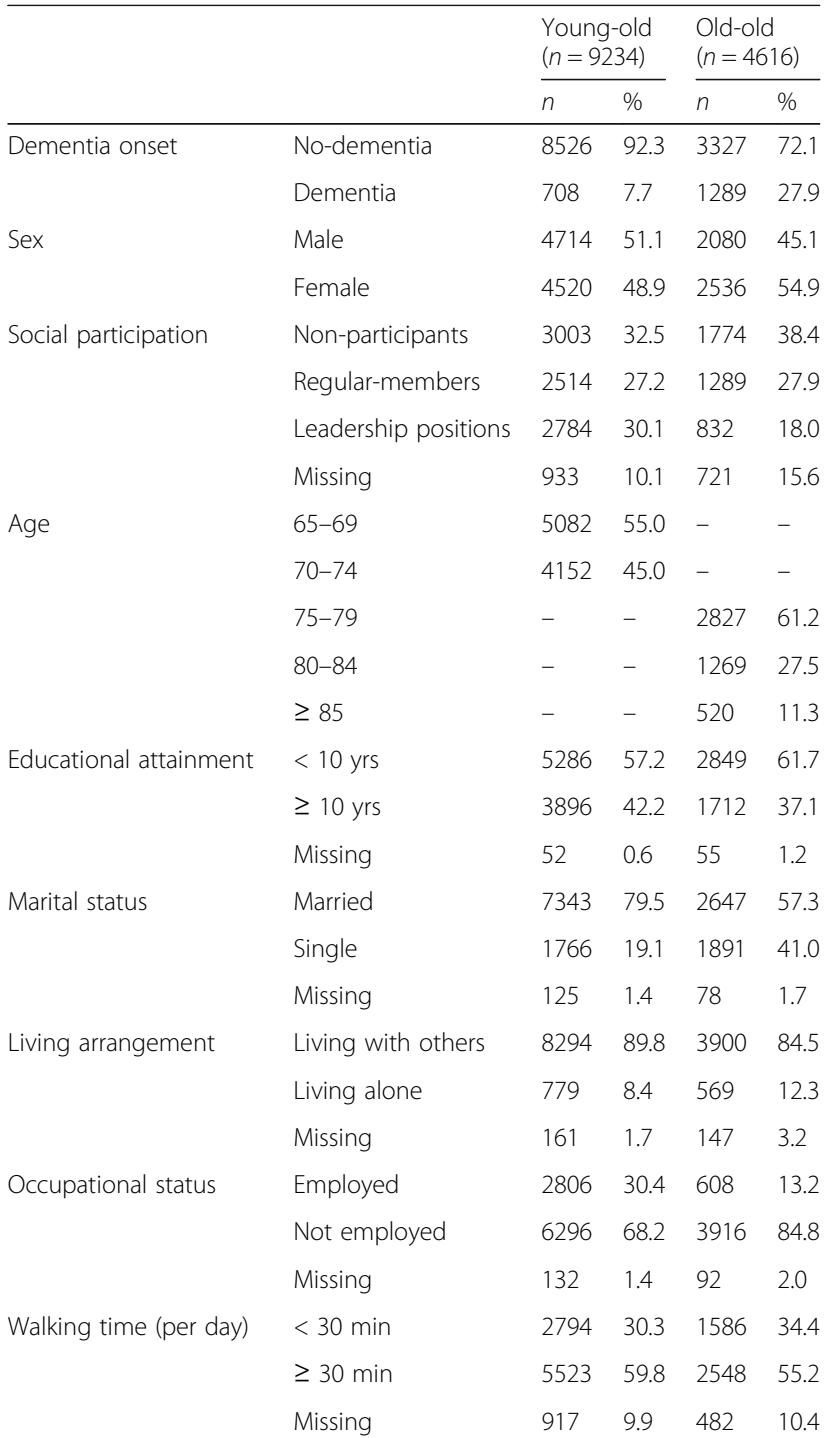

Medical history

$\begin{array}{ll}\text { Heart disease } & \text { No } \\ \text { Stroke } & \text { Yes } \\ & \text { No } \\ \text { Hypertension } & \text { Yes } \\ \text { Diabetes } & \text { Yes } \\ \text { Alcohol consumption } & \text { No } \\ & \text { Yes -drinker } \\ & \text { Drinker } \\ \text { Smoking } & \text { Missing } \\ & \text { Never smoked } \\ & \text { Past smoker/smoker } \\ & \text { Missing }\end{array}$

$\begin{array}{llll}8164 & 88.4 & 3809 & 82.5\end{array}$

$\begin{array}{llll}1070 & 11.6 & 807 & 17.5\end{array}$

$9119 \quad 98.8 \quad 4520 \quad 97.9$

$\begin{array}{llll}115 & 1.2 & 96 & 2.1\end{array}$

$\begin{array}{llll}6266 & 67.9 & 2905 & 62.9\end{array}$

$\begin{array}{llll}2968 & 32.1 & 1711 & 37.1\end{array}$

$\begin{array}{llll}8168 & 88.5 & 4157 & 90.1\end{array}$

$\begin{array}{llll}1066 & 11.5 & 459 & 9.9\end{array}$

$\begin{array}{llll}5535 & 59.9 & 3317 & 71.9\end{array}$

$\begin{array}{llll}3582 & 38.8 & 1181 & 25.6\end{array}$

$\begin{array}{llll}117 & 1.3 & 118 & 2.6\end{array}$

$\begin{array}{llll}5312 & 57.5 & 2800 & 60.7\end{array}$

$\begin{array}{llll}3615 & 39.1 & 1601 & 34.7\end{array}$

$\begin{array}{llll}307 & 3.3 & 215 & 4.7\end{array}$
Table 1 Initial characteristics of the participants (Continued)

\begin{tabular}{|c|c|c|c|c|c|}
\hline & & \multicolumn{2}{|c|}{$\begin{array}{l}\text { Young-old } \\
(n=9234)\end{array}$} & \multicolumn{2}{|c|}{$\begin{array}{l}\text { Old-old } \\
(n=4616)\end{array}$} \\
\hline & & $n$ & $\%$ & $n$ & $\%$ \\
\hline \multirow[t]{3}{*}{ Depression } & normal & 6004 & 65.0 & 2591 & 56.1 \\
\hline & depressed & 2304 & 25.0 & 1316 & 28.5 \\
\hline & Missing & 926 & 10.0 & 709 & 15.4 \\
\hline \multirow[t]{3}{*}{ IADL } & High & 7649 & 82.8 & 3196 & 69.2 \\
\hline & Low & 1335 & 14.5 & 1182 & 25.6 \\
\hline & Missing & 250 & 2.7 & 238 & 5.2 \\
\hline
\end{tabular}

social participation may help to strengthen the health benefits of social participation [24], or enable individuals to obtain information that supports a healthy lifestyle [25]. Socially-responsible activities may improve the quantity or quality of stimulation of the brain's cognitive function, or maintain better mental health [8]. However, we did not investigate the type of activity, or use laboratory data, so this is only speculation. As little is known about the mechanism behind the increased positive effect of leadership on cognitive function, further investigation is needed.

In contrast to the young-old group, there were no significant relationships between social participation or leadership and dementia onset in the old-old group. These results support the findings of previous studies $[11,26,27]$. Iwasa et al. [26] suggested that social participation was not attributed to the prevention of cognitive decline among Japanese community-dwelling elderly aged 70 years and over, based on the data from a fiveyear prospective cohort study. One possible explanation is that as the prevalence of individuals with health problems is much higher in this group than in the young-old

Table 2 Incidence rates (1000 person-years) of dementia onset by sex, age, and educational attainment

\begin{tabular}{|c|c|c|c|c|}
\hline & \multicolumn{2}{|l|}{ Young-old } & \multicolumn{2}{|l|}{ Old-old } \\
\hline & Incidence rate & $95 \% \mathrm{Cl}$ & Incidence rate & $95 \% \mathrm{Cl}$ \\
\hline \multicolumn{5}{|l|}{ Sex } \\
\hline Male & 9.3 & $8.3-10.4$ & 36.2 & $32.8-39.9$ \\
\hline Female & 9.3 & $8.4-10.5$ & 43.9 & $40.7-47.4$ \\
\hline \multicolumn{5}{|l|}{ Age } \\
\hline $65-69$ & 5.5 & $4.8-6.4$ & - & - \\
\hline $70-74$ & 14.3 & $13.0-15.8$ & - & - \\
\hline $75-79$ & - & - & 31.3 & $28.8-34.1$ \\
\hline $80-84$ & - & - & 51.5 & $46.3-57.3$ \\
\hline$\geq 85$ & - & - & 83.3 & $71.8-96.8$ \\
\hline \multicolumn{5}{|c|}{ Educational attainment } \\
\hline$<10$ yrs & 10.2 & $9.2-11.3$ & 42.6 & $39.4-45.9$ \\
\hline$\geq 10 \mathrm{yrs}$ & 8.9 & $7.8-10.1$ & 36.2 & $32.6-40.1$ \\
\hline
\end{tabular}


Table 3 Relationship between social participation and dementia onset

\begin{tabular}{|c|c|c|c|c|}
\hline & \multicolumn{2}{|l|}{ Crude } & \multicolumn{2}{|l|}{ Adjusted } \\
\hline & $\overline{\mathrm{HR}}$ & $95 \% \mathrm{Cl}$ & $\overline{\mathrm{HR}}$ & $95 \% \mathrm{Cl}$ \\
\hline \multicolumn{5}{|l|}{ Young-old $(n=9234)$} \\
\hline \multicolumn{5}{|l|}{ Social participation } \\
\hline Non-participants & reference & & reference & \\
\hline Participants & 0.64 & $0.55-0.75$ & 0.75 & $0.64-0.88$ \\
\hline \multicolumn{5}{|l|}{ Old-old $(n=4616)$} \\
\hline \multicolumn{5}{|l|}{ Social participation } \\
\hline Non-participants & reference & & reference & \\
\hline Participants & 0.73 & $0.65-0.82$ & 0.91 & $0.81-1.03$ \\
\hline
\end{tabular}

Adjusted for sex, age, educational attainment, marital status, living arrangement, occupational status, walking time, medical history, alcohol consumption, smoking, depression, and IADL

group, the relationship between social participation and dementia onset in old-old elderly may be relatively weaker than that in the young-old group. In the present study, health status such as diabetes, depression, and Independent Activity of Daily Living were strongly related to dementia onset (Additional file 1); therefore, these health problems may be the major correlated factors of incidence of dementia in old-old elderly. However, we may have underestimated this relationship in the old-old group for several reasons. First, the percentage of individuals who had died or moved out during follow-up period was much higher (29.5\%) among the old-old than young-old (17.5\%), which means that about $30 \%$ of the old-old participants had died or moved out before developing dementia. Secondly, the presence or absence of social participation and leadership were assessed at baseline, but prior experience was not assessed; therefore, old-old participants who had experienced social participation or leadership before the assessment but had already retired from these activities at the time of baseline assessment

Table 4 Relationship between having a leadership positions and dementia onset

\begin{tabular}{|c|c|c|c|c|}
\hline & \multicolumn{2}{|l|}{ Crude } & \multicolumn{2}{|l|}{ Adjusted } \\
\hline & $\overline{\mathrm{HR}}$ & $95 \% \mathrm{Cl}$ & $\overline{\mathrm{HR}}$ & $95 \% \mathrm{Cl}$ \\
\hline \multicolumn{5}{|l|}{ Young-old $(n=9234)$} \\
\hline Regular-members & reference & & reference & \\
\hline Non-participants & 1.38 & $1.15-1.64$ & 1.22 & $1.02-1.46$ \\
\hline Leadership positions & 0.76 & $0.61-0.94$ & 0.81 & $0.65-0.999$ \\
\hline \multicolumn{5}{|l|}{ Old-old $(n=4616)$} \\
\hline Regular-members & reference & & reference & \\
\hline Non-participants & 1.30 & $1.15-1.48$ & 0.99 & $0.86-1.13$ \\
\hline Leadership positions & 0.86 & $0.72-1.02$ & 0.98 & $0.83-1.14$ \\
\hline
\end{tabular}

Adjusted for sex, age, educational attainment, marital status, living arrangement, occupational status, walking time, medical history, alcohol consumption, smoking, depression, and IADL were categorized as non-members. Thus, in this study, the category of non-member in the old-old group contained those who were non-members later in life and those who were members before the study period. These reasons can be attributed to underestimation of the association between social participation and incidence of dementia. Further studies of the association of social participation with dementia onset in old-old elderly people are needed.

This study has several limitations. First, the incidence of dementia in this study was obtained from the results of an examination and judgment by the Certification Committee of Needed Long-Term Care in the participant's municipality. Therefore, underestimation of dementia incidence might have occurred, because every dementia patient does not necessarily submit an application to the Certification Committee. Second, as the type of dementia was not assessed, such as Alzheimer disease, vascular dementia, or Lewy body dementia, the effect of social participation or leadership on each type of dementia remained unclear. Third, the response rate of the baseline survey was $52.1 \%$, meaning that nonresponders may have induced selection bias. In this study, the characteristics of non-responders were unknown, but we think it is possible that old-old people or those with lower health status may have been less likely to respond to the survey. There may therefore have been differences in baseline characteristics between study participants and non-participants. Fourth, as the experience of social participation or leadership before the baseline survey was not assessed, the relationship between social participation and dementia onset may be affected by the results of these factors, especially among old-old participants. Future studies evaluating this association should take into account the subject's experience of social participation and leadership before the baseline survey. Fifth, this study could not identify which types of social activity or leadership were related to the incidence of dementia. Further studies are needed to examine this issue, especially qualitative studies that assess the influence of social participation or a leadership role on older adults' daily lives. Finally, as the assessment of social participation and leadership were carried out only at the baseline survey, the influence of change in status of participation during the follow-up period on the relationship was not clear.

In summary, despite the above-mentioned limitations, this study revealed that social participation might have a repressive effect on the incidence of dementia and also leadership within the activity group might have stronger positive effect on dementia incidence among young-old adults. These finding should be used to encourage young-old adults to participate in and take leadership positions in social activity organizations. 


\section{Conclusions}

In young-old elderly people, social participation might have a positive effect on the prevention of dementia onset, and leadership within a group may lead to a reduction of risk of dementia onset of almost $20 \%$, compared with regular members.

\section{Additional file}

Additional file 1: Relationship between having a leadership positions and dementia onset in old-old. (XLSX $13 \mathrm{~kb}$ )

\section{Acknowledgements}

We would like to thank the study participants, and also express our appreciation to all the central office staff members for collecting the baseline survey and follow-up data. We would also like to thank members of the JAGES group for their advice about this study.

\section{Funding}

This study was supported by a Grant-in-Aid for Scientific Research (KAKENHI) (Nos. 23,243,070, 25,253,052, 15H01972) from the Japanese Society for the Promotion of Science, a Comprehensive Research on Aging and Health Grant (H25-Chouju-Ippan-003) 2013-2015 from the Japanese Ministry of Health, Labour and Welfare, a Health Labor Sciences Research Grant (H25-kenki-wakate015, H28-Chouju-Ippan-002) from the Japanese Ministry of Health, Labour and Welfare; and the Japan Agency for Medical Research and Development. The funders had no role in study design, data collection and analysis, decision to publish, or preparation of the manuscript.

\section{Availability of data and materials}

The dataset is available to the researcher who submit research proposal to the JAGES committee (https://www.jages.net/) and permit to use this dataset.

\section{Authors' contributions}

Study conception and design: YN TS SK TT KS HK KM TA KK. Acquisition of data: KK The JAGES Group. Analysis and interpretation of the data: YN KM TA. Drafting the paper: YN TA. Critical revision: TS SK TT KS HK MK TA KK. All authors read the manuscript and approved the submission.

\section{Ethics approval and consent to participate}

We obtained written consent from the participants. The protocol of AGES project was approved by the Ethics Committee on Research of Human Subjects at Nihon Fukushi University.

\section{Consent for publication}

Not Applicable.

\section{Competing interests}

The authors declare that they have no competing interests.

\section{Publisher's Note}

Springer Nature remains neutral with regard to jurisdictional claims in published maps and institutional affiliations.

\footnotetext{
Author details

${ }^{1}$ Graduate School of Sports Sciences, Waseda University, Saitama, Japan. 2Department of Social Science, National Center for Geriatrics and Gerontology, Obu City, Aichi, Japan. ${ }^{3}$ Department of Preventive Medicine and Public Health, Tokyo Medical University, Tokyo, Japan. ${ }^{4}$ Human Resource Management Department, ITOCHU Techno-Solutions Corporation, Tokyo, Japan. ${ }^{5}$ Center for Preventive Medical Sciences, Chiba University, Chiba, Japan. ${ }^{6}$ Department of Human Sciences, School of Law and Letters, University of the Ryukyus, Okinawa, Japan. ${ }^{7}$ Department of Clinical Epidemiology, Translational Medical Center, National Center of Neurology and Psychiatry, Tokyo, Japan. ${ }^{8}$ Faculty of Sports Sciences, Waseda University, 干359-1164 Saitama Prefecture, Tokorozawa, Mikajima, 2-579-15, Saitama, Japan. ${ }^{9}$ Center for Well-being and Society, Nihon Fukushi University, Mihama,
}

Aichi, Japan. ${ }^{10}$ Department of Gerontology and Evaluation Study, Center for Gerontology and Social Science, National Center for Geriatrics and Gerontology, Obu City, Aichi, Japan.

Received: 3 July 2017 Accepted: 12 December 2017

Published online: 29 December 2017

\section{References}

1. World Health Organization. Dementia: a public health priority, World Health Organization. 2012. Available: http://apps.who.int/iris/bitstream/10665/ 75263/1/9789241564458 eng.pdf?ua=1. Accessed 4 Mar 2017.

2. Ministry of Health, Labour and Welfare. Long-Term Care Insurance System of Japan. Available: http://www.mhlw.go.jp/english/policy/care-welfare/carewelfare-elderly/dl/Itcisj_e.pdf. Accessed 26 Apr 2017.

3. Beydoun MA, Beydoun HA, Gamaldo AA, Teel A, Zonderman AB, Wang Y Epidemiologic studies of modifiable factors associated with cognition and dementia: systematic review and meta-analysis. BMC Public Health. 2014;14:643.

4. Blondell SJ, Hammersley-Mather R, Veerman JL. Does physical activity prevent cognitive decline and dementia?: a systematic review and metaanalysis of longitudinal studies. BMC Public Health. 2014;14:510.

5. Kuiper JS, Zuidersma M, Oude Voshaar RC, Zuidema SU, van den Heuvel ER, Stolk RP, et al. Social relationships and risk of dementia: a systematic review and meta-analysis of longitudinal cohort studies. Ageing Res Rev. 2015;22:39-57.

6. Fujiwara $Y$, Sugihara $Y$, Shinkai S. Effects of volunteering on the mental and physical health of senior citizens significance of senior-volunteering from the view point of community health and welfare. Nihon Koshu Eisei Zasshi. 2005;52:293-307.

7. Ishikawa Y, Kondo N, Kondo K, Saito T, Hayashi H, Kawachi I, et al. Social participation and mortality: does social position in civic groups matter? BMC Public Health. 2016:16:394.

8. Takagi D, Kondo K, Kawachi I. Social participation and mental health: moderating effects of gender, social role and rurality. BMC Public Health. 2013;13:701

9. Shock NW. Physical activity and the "rate of ageing". Can Med Assoc J. 1967; 96(12):836-42

10. Nishi A, Kondo K, Hirai H, Kawachi I. Cohort profile: the AGES 2003 cohort study in Aichi, Japan. J Epidemiol. 2011;21:151-7.

11. Kondo K. Health inequality in Japan: an empirical study of older people. Melbourne: Trans Pacific Press; 2010.

12. Matsuda S, Yamamoto M. Long-term care insurance and integrated care for the aged in Japan. Int J Integrated Care. 2001;1:1-11.

13. Yamamoto T, Kondo K, Hirai H, Nakade M, Aida J, Hirata Y. Association between self-reported dental health status and onset of dementia: a 4-year prospective cohort study of older Japanese adults from the Aichi Gerontological evaluation study (AGES) project. Psychosom Med. 2012;74:241-8.

14. Ministry of Health, Labour and Welfare. The text for the members of Longterm Care Approval Board 2009 revision. Available: http://www.mhlw.go.jp/ english/policy/care-welfare/care-welfare-elderly/dl/ltcisj_e.pdf. Accessed 3 Nov 2017

15. Hisano $\mathrm{S}$. The relationship between revised Hasegawa dementia scale (HDS-R), mini-mental state examination (MMSE) and bed-fast scale, dementia scale. Ronen Seishin Igaku Zasshi. 2009;20:883-91. [In Japanese.]

16. Osaka university commerce JGSS Research Center. Summary of Surveys. Available: http://jgss.daishodai.ac.jp/english/surveys/sur_top.html. Accessed 3 Nov 2017

17. Koyano W, Shibata H, Nakazato K, Haga H, Suyama Y. Measurement of competence: reliability and validity of the TMIG index of competence. Arch Gerontol Geriatr. 1991;13:103-16.

18. Burke WJ, Roccaforte WH, Wengel SP. The short form of the geriatric depression scale: a comparison with the 30-item form. J Geriatr Psychiatry Neurol. 1991:4:173-8.

19. Nyunt MS, Fones C, Niti M, Ng TP. Criterion-based validity and reliability of the geriatric depression screening scale (GDS-15) in a large validation sample of community-living Asian older adults. Aging Ment Health. 2009;13:376-82

20. Demirtas $H_{1}$ Hedeker D. An imputation strategy for incomplete longitudinal ordinal data. Statist Med. 2008;27:4086-93.

21. Rubin DB. Multiple imputation for nonresponse in surveys. New York: Wiley; 1987. 
22. Fratiglioni $\mathrm{L}$, Paillard-Borg S, Winblad B. An active and socially integrated lifestyle in late life might protect against dementia. Lancet Neurol. 2004;3: 343-53.

23. Hultsch DF, Hertzog C, Small BJ, Dixon RA. Use it or lose it: engaged lifestyle as a buffer of cognitive decline in aging? Psychol Aging. 1999;14:245-63.

24. Wilson RS, Krueger KR, Arnold SE, Schneider JA, Kelly JF, Barnes LL, et al. Loneliness and risk of Alzheimer disease. Arch Gen Psychiatry. 2007;64:234-40.

25. Kobayashi LC, Wardle J, von Wagner C. Internet use, social engagement and health literacy decline during ageing in a longitudinal cohort of older English adults. J Epidemiol Community Health. 2015;69:278-83.

26. Iwasa H, Yoshida Y, Kai I, Suzuki T, Kim H, Yoshida H. Leisure activities and cognitive function in elderly community-dwelling individuals in Japan: a 5-year prospective cohort study. J Psychosom Res. 2012;72:159-64.

27. Gureje O, Ogunniyi A, Kola L, Abiona T. Incidence of and risk factors for dementia in the Ibadan study of aging. J Am Geriatr Soc. 2011;59:869-74.

Submit your next manuscript to BioMed Central and we will help you at every step:

- We accept pre-submission inquiries

- Our selector tool helps you to find the most relevant journal

- We provide round the clock customer support

- Convenient online submission

- Thorough peer review

- Inclusion in PubMed and all major indexing services

- Maximum visibility for your research

Submit your manuscript at www.biomedcentral.com/submit 